\title{
SAMs of 2-Aminoethanethiol Modified with 3,4-Dihydroxyphenylalanine for the Electrocatalytic Oxidation of NADH on Gold Electrodes
}

\author{
Seong-Keuck Cha \\ Deparment of Chemistr, Kyungnam Lniversity, Masan 631-701. Korea \\ Received December 28,2003
}

\begin{abstract}
2-Aninoethanethiol (aet) has been used to make self-assembled monolayer (SAMs) on gold electrodes, which are subsequently modified with 3.4-dihydroxy phenylalanine (dpa). Such modified electrodes having various types of Au/aet-dpa were employed in the electrocatalytic oxidation of NADH. The purpose of this study to characterize the responses of such modified electrodes in terms of the immobilization procedure, $\mathrm{pH}$ of the solution and applied potential. The reaction of the surface imınobilized dpa with NADH was studied using the rotating disk electrode technique and a value of $2.2 \times 10^{1} \mathrm{M}^{1} \mathrm{~s}{ }^{1}$ was obtained for the second-order rate constant in $0.1 \mathrm{M}$ Tris $/ \mathrm{NO}_{3}$ buffer ( $\mathrm{pH}=8.0$ ). The hydration behavior of the films was characterized by quartz crystal microbalance. When used as a NADH sensor, the Au/aet-dpa electrode exhibited good sensitivity and an excellent correlation $(r \geq 0.99)$ for NADH concentration which extended to $3.8 \times 10^{3} \mathrm{M}$.
\end{abstract}

Key Words : 2-Aminochanethiol, 3.4-Dihydroxy phenylalanine, NADH

\section{Introduction}

Self-assembled monolayers (SAMs) of ultra thin organic films have been widely used to control surface properties and in basic studies of interfacial phenomena at electrodeelectrolyte interfaces. The formation. ' structure, $^{2}$ properties $^{3}$ and applications of SAMs of n-alkanethiols on metal surfaces $^{4}$ have been particularly well studied. Alkyl chains consisting of fewer than 15 carbon atom have been found to be disordered. ${ }^{5}$ In the case of the longer chains the order and structural stability are greatly improved, owing to the formation of the hydrogen bonds between the strands of the SAMs. ${ }^{5}$ In general, the bonds between the metal and the SAM do not give rise to contact resistance problems associated with the metallic substrates and polymeric films used in polymer modified electrode (PMEs). In the case of the PME, the morphology of the film layer can affect the resistance.

The cysteine molecule with three functional groups such as amine, carboxyl and thiol, can give rise to SAMs on gold via the cysteine molecule's thiol group. The remaining functional groups can then be used for further modifications. For example, the amine group can react with a carboxylic functionality to yield an amide bond. Molecules, such as 3.4dihydroxybenzaldehyde, 3,4-dihydroxybenzoic acid, arterenol, dopamine and 3.4-dihydroxyphenylalanine, having an o-quinone moiety, exhibit quinone bond redox processes at a formal potential of +0.2 to $+0.4 \mathrm{~V}(\mathrm{ws}$. SCE) with pendant amino group. The latter three materials could be made to react with carboxylic acids by using a coupling agent such as 1-(3-dimethylaminopropyl)-3-ethylcarbodiimide (EDC).

In this work, we employed 2-aminoethanethiol (aet) and 3,4-dihydroxyphenylalanine (dpa) to prepare SAMs on gold surfaces as shown on Scheme 1. In this approach, the gold

c-mail: chask@kyungnam.ac.kr

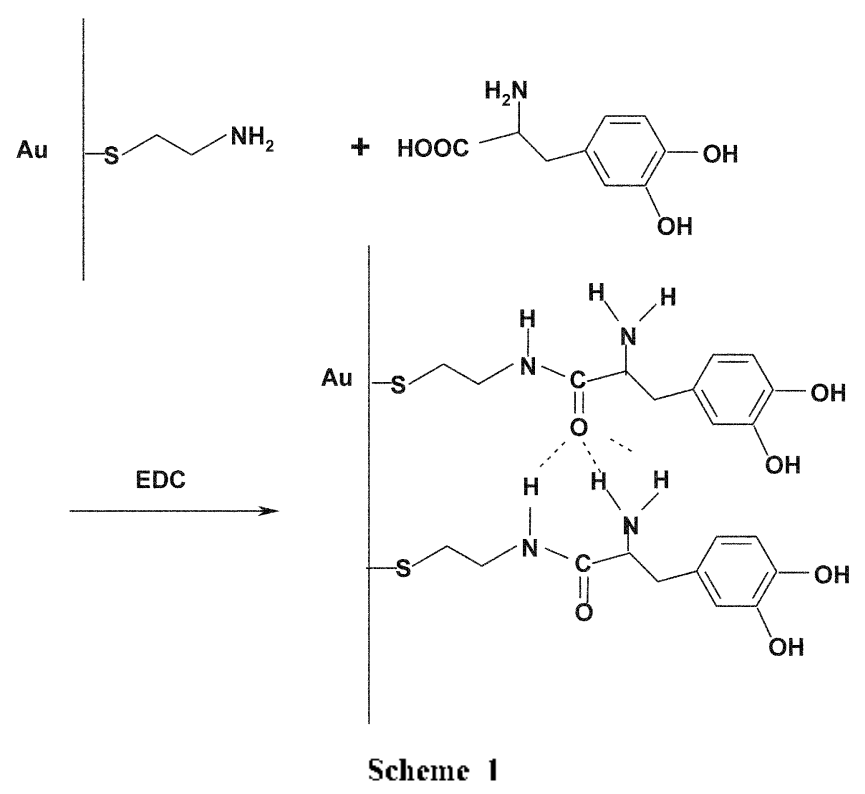

surface is first modified with 2-aminoethanethiol (aet) and subsequently reacted with dpa to give rise to a surface immobilized o-hydroquinone, which can produce various hydrogen bond formations among the strands of the SAMs.

In this study, we present the preparation and characterization of such electrodes, as well as their activity in the electrocatalytic oxidation of $\mathrm{NADH}^{\text {? }}$

\section{Experimental Section}

Instruments and chemicals. Electrochemical experiments were performed using an $\mathrm{EG} \& \mathrm{G} 273 \mathrm{~A}$ potentiostat/ galvanostat with $270 / 250$ software. Data were recorded on a Philips model $8043 \mathrm{X}-\mathrm{Y}$ recorder and plotter (HP color pro). Potentials were measured and reported against sodium saturated calomel electrode (SSCE). Cyclic voltammetry 
(CV) was used to evaluate the redox characteristics of the reactions and for the $\mathrm{NADH}$ determinations. A quart7 crystal microbalance (CHI 420,USA) was employed for electrochemical quartz crystal microbalance (FQCM) experiments.

Gold electrodes were constructed by producing small beads with diameters of $0.2-0.3 \mathrm{~mm}$ from $0.1 \mathrm{~mm}$ gold wire heated with an oxygen/propane flame. The beads were subsequently sealed in soft glass. The electrodes, initially polished with sand paper, were subsequently polished with diamond paste (Struers, Denmark; l $\mu \mathrm{m}$ ) to generate a mirror-like surface. Before they were used the electrodes were cleaned with Piranha solution $\left(\mathrm{H}_{2} \mathrm{O}_{2}: \mathrm{H}_{2} \mathrm{SO}_{4}=1: 3\right)$ to remove the organics. High-cuality deionized water (18 M $\Omega$ ) was obtained from a Millipore Mili-Q system, Dopamine was recrystallized three time from ethanol/water and dried at $75^{\circ} \mathrm{C}$ for 24 hrs under reduced pressure. $0.1 \mathrm{M}$ phosphate $(\mathrm{pH}=5.52), 0.1 \mathrm{M}$ phosphate $(\mathrm{pH}=7.10)$ and $0.1 \mathrm{M}$ Tris $\mathrm{NO}_{3}^{-}(\mathrm{pH}=8.00)$ buffers were prepared from analytical grade reagents. 3,4-dihydroxyphenylalanine, FDC and $\mathrm{NADH}$ were purchased from Aldrich and used as received.

Electrode modification. A monolayer of 2-aminoethanethiol was formed by immersing a pretreated gold electrode in a $1.0 \mathrm{mM}$ aet $/$ water solution for 60 minutes. For well ordered SAMs, the electrodes were annealed by CV for $5 \mathrm{~min}$ in the potential range of -0.2 to $+0.6 \mathrm{~V}$ with a scan rate of $50 \mathrm{mV} / \mathrm{s}$ and subsequently immersed in $1.5 \mathrm{mM}$ dpa at 0.1 $\mathrm{M}$ phosphate buffer solution $(\mathrm{pH}=7.1)$ containing $3.0 \mathrm{mM}$ EDC for 3 hrs to obtain various types of Au/aet-dpa modified electrodes. These modified electrodes annealed in ethanol for $6 \mathrm{~h}$. The SAMs were found to be stable for repeated uses at the potential ranges of $-0.40 \mathrm{~V}$ to $0.80 \mathrm{~V}$. The changes in mass accompanying the formation of the monolayer, reaction with dpa and hydration changes during the redox reactions were characterized with an FQCM.

Determination of NADH. The oxidation of the surface immobilized o-hydroquinone moiety of dpa was performed at $0.15 \mathrm{~V}$ in Tris $\mathrm{NO}_{3}^{-}$buffer $(\mathrm{pH}=8.0)$ in the electrocatalytic oxidation of $\mathrm{NADH}$ in solution. ${ }^{8}$

\section{Results and Discussion}

CV results. The coenzyme immobilized on the Au/aetdpa electrode acts as an acceptor of electrons generated in the reaction and is converted to its reduced NADH. Figure I shows the CVs results for the Au/aet-dpa electrode using (A) a $0.1 \mathrm{M}$ phosphate buffer solution ( $\mathrm{pH}=5.52)$, (B) a $0.1 \mathrm{M}$ phosphate buffer solution ( $\mathrm{pH}=7.1)$, and $(\mathrm{C})$ a $0.1 \mathrm{M}$ 'ris $\mathrm{NO}_{3}^{-}$buffer solution ( $\mathrm{pH}=8.0$ ) for a single cycle (top) and various sweep rates (bottom). The formal potentials for the above three cases were $0.21,0.26$ and $0.30 \mathrm{~V}$, respectively. From these results which are shown in Figure 1 , it was found that $\mathrm{A}$ and $\mathrm{C}$ were good conditions for promoting the oxidation reaction of the cofactor. As shown in the $\mathrm{CV}$ results, the waves had the expected shape for a surface immobilized redox center with a small tep value. Also, the current was directly proportional to the rate of potential sweep over the range of 10 to $500 \mathrm{mV} / \mathrm{s}$ (Fig. 2), suggesting

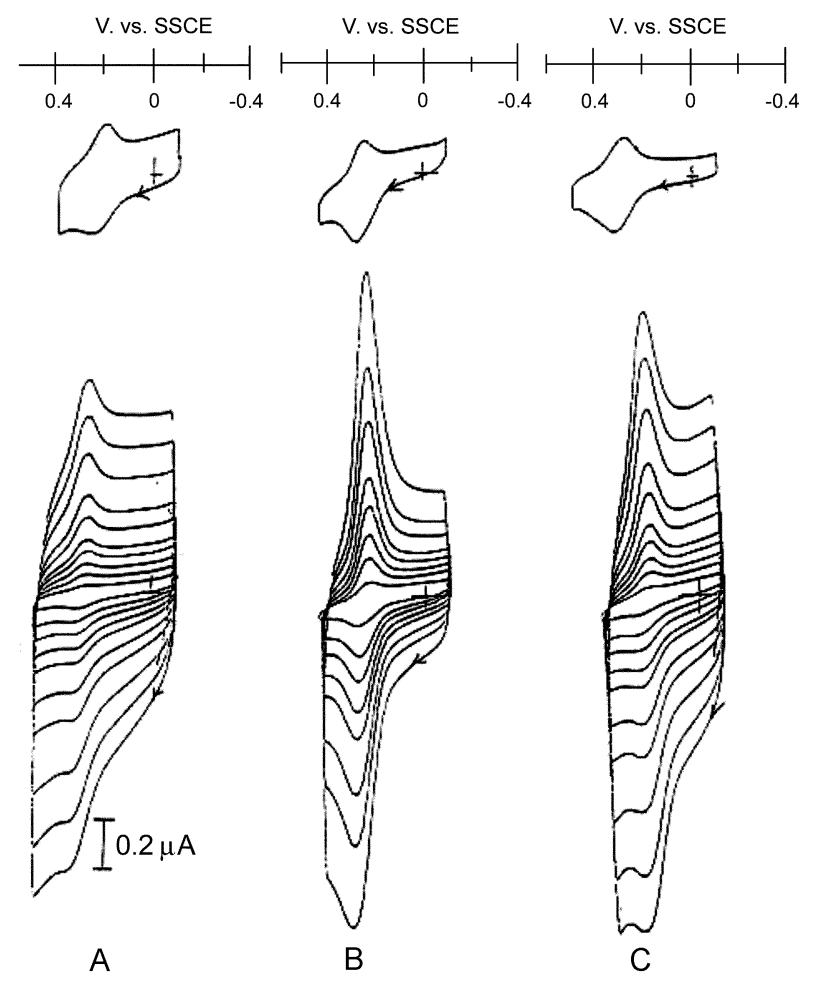

Figure 1. The $C V$ s results tor the Nu/ael-dpa electrodes. for an applied potential range of -0.1 to $0.5 \mathrm{~V}$ in $(\Lambda) 0.1 \mathrm{M}$ phosphate hutfer ( $\mathrm{pH}=5.52)$. (B) $0.1 \mathrm{M}$ phosphate huffer $(\mathrm{pH}=7.1$ ) and (C) $0 . \mathrm{I}$ $\mathrm{M}$ tris $\mathrm{NO}_{3}{ }^{-}$bulfer $(\mathrm{pH} 8.0)$. with a sweep rate of $50 \mathrm{mVs}^{-1}(1 \mathrm{pp})$ and an electrode area of $7.07 \times 10^{-2} \mathrm{~cm}^{2}$. The sweep rale dependences of the electrodes were 10.30.50.75. 100. 150. 200 . 300.400 and $500 \mathrm{~m} \mathrm{Vs}^{-1}$.

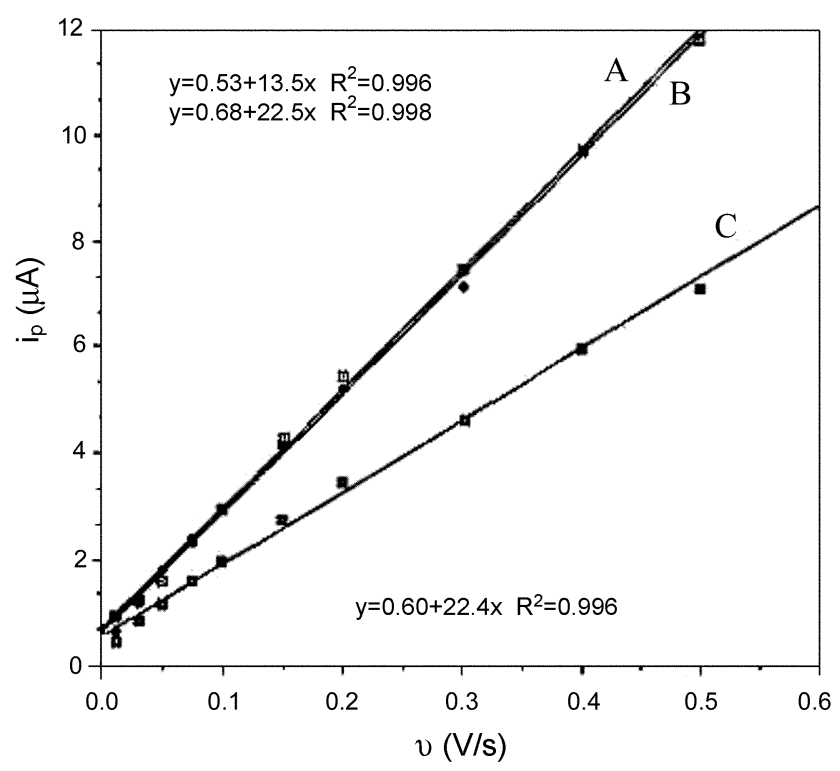

Figure 2. Plot of anodic peak current is sireep rate for each clectrode of Fig. I. respectively.

the existence of facile charge transfer kinetics in each buffer solution. These films were quite stable, as long as the applied potential did not exceed $+0.80 \mathrm{~V}$. Then, dpa, as a tyrosine derivative molecules, ${ }^{9}$ could be dimerized due to the 

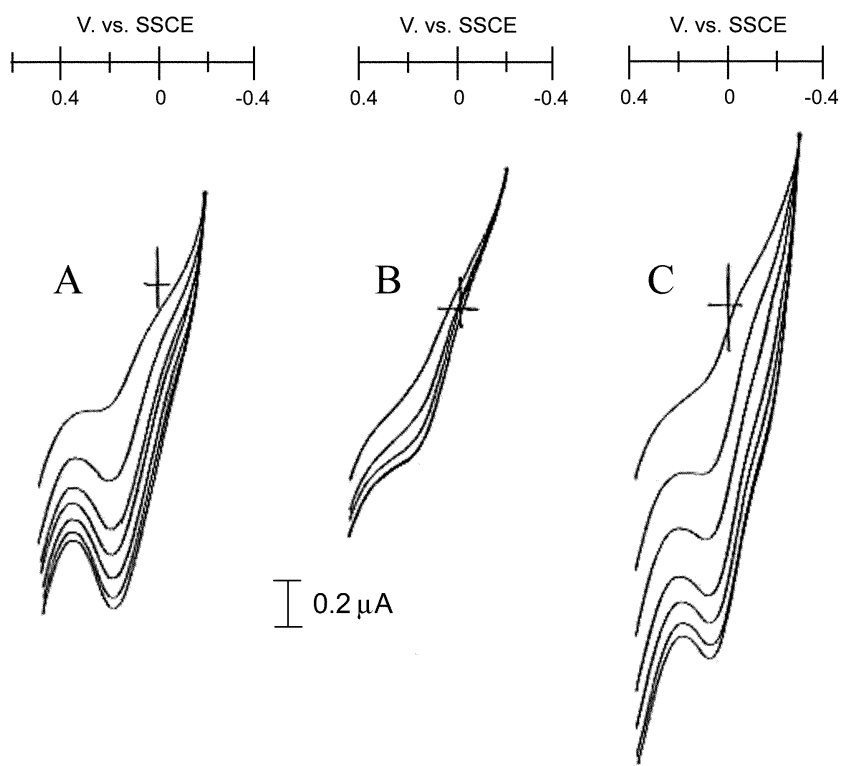

Figure 3. Lincar swcep voltammetric responses with sweep rate of $10 \mathrm{mV} / \mathrm{s}$ at RDFF(Au) aet-dpa electrodes (A) in $0.1 \mathrm{M}$ phosplate but Yer ( $\mathrm{pl}=5.52$ ). (13) $0.1 \mathrm{M}$ phosphale bulfer $(\mathrm{pl}=7.1$ ) and $(\mathrm{C}) 0.1$ $\mathrm{M}$ tris $\mathrm{NO}_{3}^{-}$butfer $(\mathrm{pl}=8.0$ ) containing $0.3 \mathrm{I} \mathrm{mM}$ [NADII] solution, with rotaling rates of 0 to $2500 \mathrm{rmm}$ at $500 \mathrm{rmm}$ intervals. The coverage of the $S \wedge \mathrm{Ms}$ was $1.05 \times 10^{-10}$, the electrode area was $7.07 \times 10^{2} \mathrm{~cm}^{2} .10 \mathrm{mVs}$ !

presence of F.DC. For the coupling reaction on the film of the electrode surface to take place, concentration of the molecules has to be kept at more than $1.0 \mathrm{mM}$.

Rotating disk electrode (RDE). The kinetic parameters were measured from RDF experiments. The catalytic current for NADH oxidation at the Au/aet-dpa electrodes was measured in $0.1 \mathrm{M}$ Tris $\mathrm{NO}_{3}^{-}$buffer $(\mathrm{pH}=8.0$ ) containing $0.31 \mathrm{mM} \mathrm{NADH}$. The results obtained using an electrode with the surface coverage of $1.05 \times 10^{-10} \mathrm{~mol}_{\mathrm{cm}}^{-2}$ are shown on Figure $3 \mathrm{~A}$. The current increased with increasing

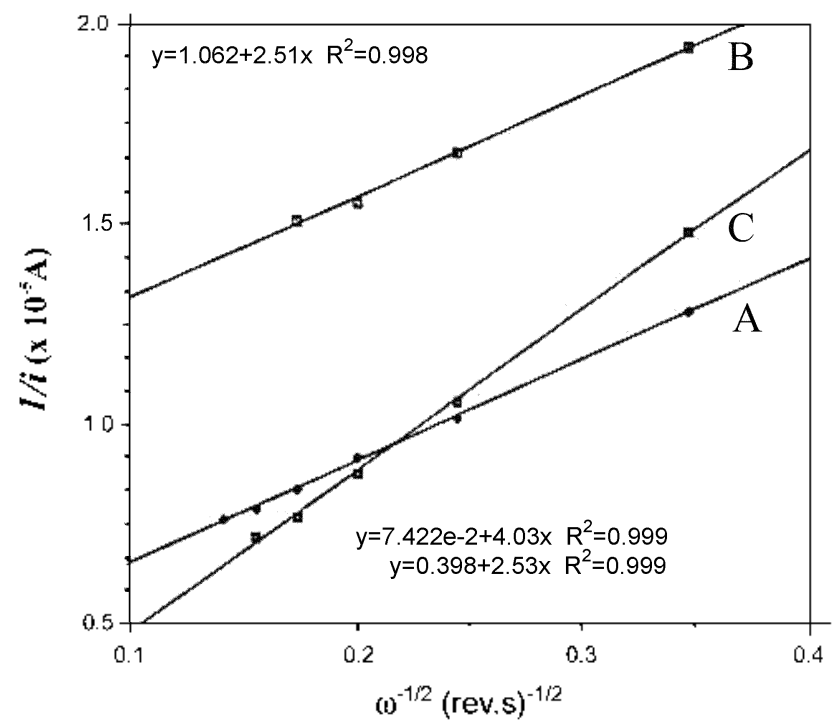

Figure 4. The reverse Koutcky-Levich plots for the data showin in Fig. 3. respectively. revolution rate $\omega$ up to $2,500 \mathrm{rpm}$. Also, a reverse KoteckyI evich plot of $i^{-1} \mathrm{vs} \omega^{-1 ; 2}(\mathrm{Fig}$. 4) was found to be linear up to $3.77 \mathrm{mM}[\mathrm{NADH}$, suggesting the existence of kinetic limitations. The corresponding equation ${ }^{10}$ is

$$
1 / i_{\mathrm{lim}}-1 /\left(\mathrm{nFAk}_{\mathrm{f}} \Gamma \mathrm{C}^{*}\right)+1 /\left(0.62 \mathrm{nFA} v^{-1 / 6} \mathrm{D}^{2 / 3} \mathrm{C}^{*} \omega^{1: 2}\right)
$$

where $\mathrm{C}^{*}$ is the bulk concentration of the reactant, $\mathrm{NADH}, \Gamma$ is the surface coverage, $v$ is the kinematic viscosity, $\omega$ is the rotating rate and $\mathrm{k}_{r}$ is the rate constant. From the intercepts of the plots, the values of $k_{p}$, presenting the second-order rate constants, were $4.1 \times 10^{3}:$ (A), $1.5 \times 10^{3}:$ (B) and $2.2 \times 10^{1}$ $\mathrm{M}^{-1} \mathrm{~s}^{-1}$; (C) with the last of the constants being in value higher than the others. ${ }^{8}$ In this latter case, the electrode has well ordered surface confined cathecol moieties that enable fast electron transfer. In these systems, the NADH is more easily oxidized by the surface confined cathecol moiety in a chemical step controlled by the rate constant, $k_{r}$. The $\mathrm{NAD}^{-}$ is a product of this reaction."

Determination of NADH. The CV results shown in Figure $5 \mathrm{~A}$ are the responses at a sweep rate of $10 \mathrm{mV} / \mathrm{s}$ for the Au/cet-dpa electrodes in Tris $\mathrm{NO}_{3}^{-}$buffer solution $(\mathrm{pH}=8.0)$ for $\mathrm{NADH}$ concentrations of $0,0.38,1.13,2.26$, 3.77 and $5.66 \mathrm{mM}$ beginning from the left, respectively. The
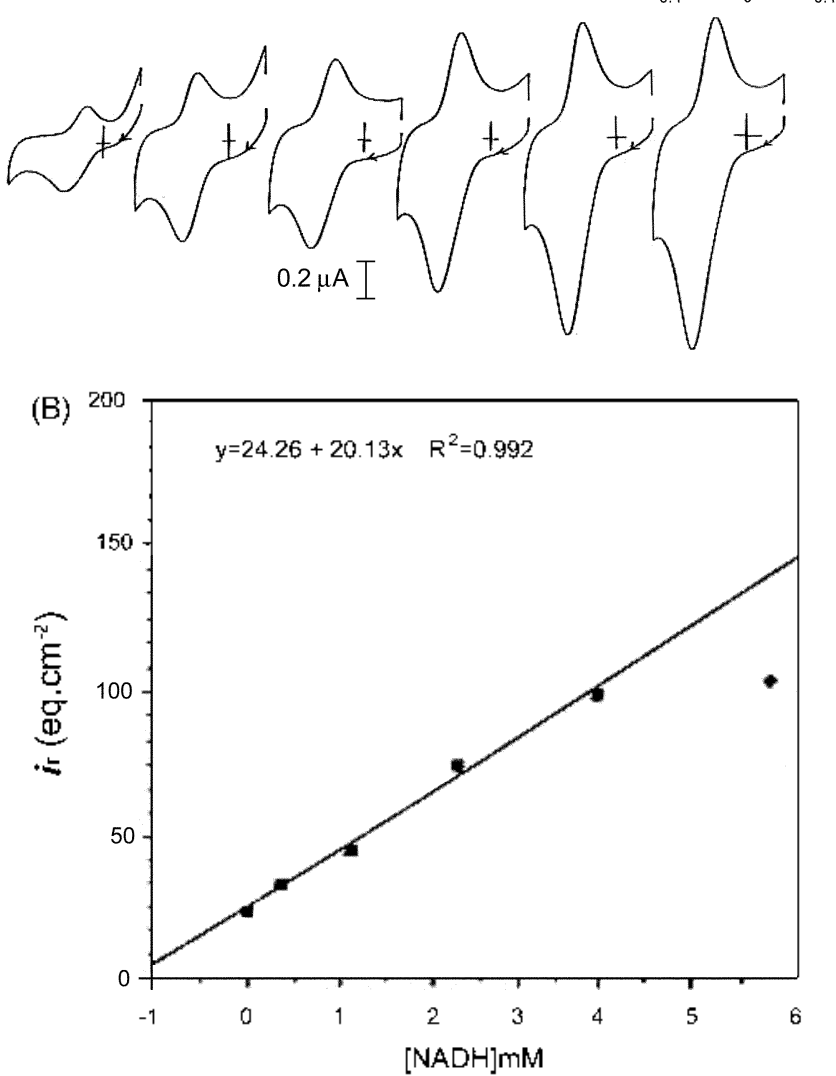

Figure $5 .(\Lambda) C V$ s responses of the $\Lambda u /$ act-dpa electrodes at 10 $\mathrm{mV} / \mathrm{s}$ in $0.1 \mathrm{M} \mathrm{Tris} / \mathrm{NO}_{3}^{-}$bufficr $(\mathrm{pH}=8.0)$ with $\mathrm{NADH}$ concenttration of $0.0 .38 .1 .13 .2 .26 .3 .77 .5 .66 \mathrm{mM}$ and $(\mathrm{B})$ calibtation curve (plot of normalized current v's. concentration) from the data of $\Lambda$. 


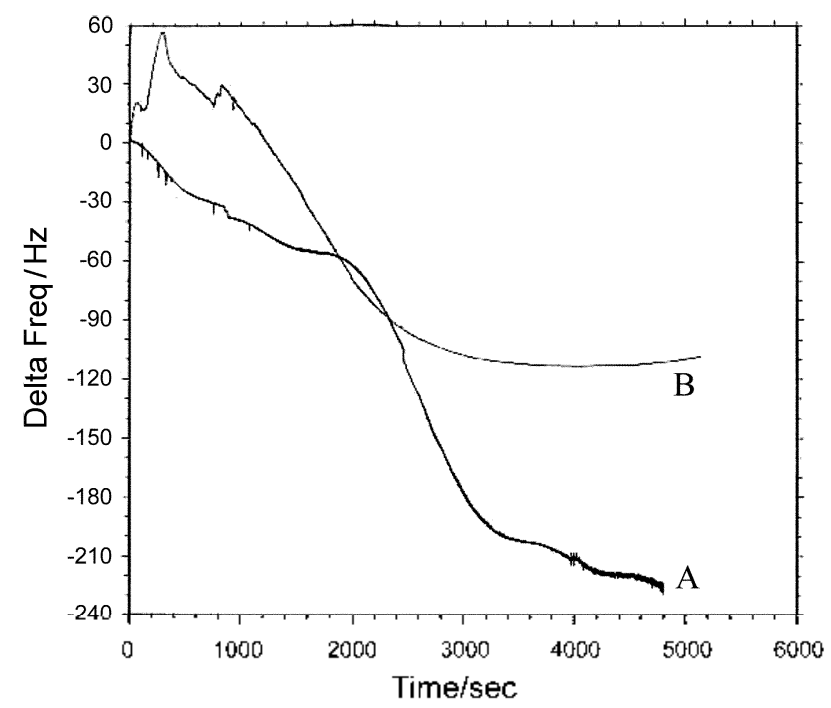

Figure 6. The frequency-time curve for the formation of SAMs with (A) 2-aminoethanethiol on $\mathrm{QCA}(\mathrm{Au})$ and $(\mathrm{B})$ modited with 3.4-dihydroxyphenylatanine on $\mathrm{QCN}(\mathrm{A}(\mathrm{u})$ atel electrode.

buffer solution gave the best results in terms of the activity of the $\mathrm{NADH}$ in solution, when the electrode was annealed in ethanol for more than 6 hrs, which gave fast kinetics for the oxidation reaction. This is evident from the fact that at the lower concentrations, the anodic peak current increases with increasing $[\mathrm{NADH}]$ but then remains fairly constant at 3.8 $\mathrm{mM}$ and over in the calibration curve, as shown on Figure $5 \mathrm{~B}$. Also, note that there is not significant return (cathodic) wave originating from the catalytic ability of this electrode. It could be that there is a limitation, due to a problem of accessibility, so that only a part of the NADH has access to the catalytic sites. These types of SAMs electrodes could be sensitive to the air with a conseguent reduction in kinetics. and could be conserved in degassed ethanol for several weeks.

EQCM results. In case of the SAMs formed with 2aminoethanethiol on $\mathrm{Au}(\mathrm{QCA})$ resonator, the frequency change as shown in Figure $6 \mathrm{~A}$ was $226.9 \mathrm{~Hz}$, but when it was coupled with dpa, this resulted in a frequency difference of $110.4 \mathrm{~Hz}$, as shown in Figure $6 \mathrm{~B}$. In the adsorption measurements of dpa on the Au/aet electrode ( $\mathrm{Fig} .6 \mathrm{~B}$ ), the frequency of $58 \mathrm{~Hz}$ which was observed for the first 30 seconds, gave way to a subsequent increase. which was caused by the desorption of weakly bound SAMs on the surface. The quantity for each electrode corresponded to $3.02 \times 10^{4}$ and $1.47 \times 10^{4} \mathrm{M} \mathrm{cm}^{-2}$, respectively. Figure $7 \mathrm{~A}$ to Figure $7 \mathrm{C}$ show the potential dependence upon frequency and the corresponding $\mathrm{CV}$ results of the various types of electrode, namely $\mathrm{QCA}(\mathrm{Au})$ /aet, $\mathrm{QCA}(\mathrm{Au}) / \mathrm{aet}-\mathrm{dpa}$ and $\mathrm{QCA}(\mathrm{Au})$ /aet-dpa-NADH in the buffer solution $(\mathrm{pH}=8.0)$ respectively. The values of frequency difference for these three electrodes were $2.8=1,6.7=1$ and $3.9 \pm 1 \mathrm{~Hz}$, which corresponded to the number of hydrated water molecules, which were 17,46 and 25 , respectively. These numbers were calculated from the Sauerbrey equation, which is shown as eq. (2). ${ }^{12}$
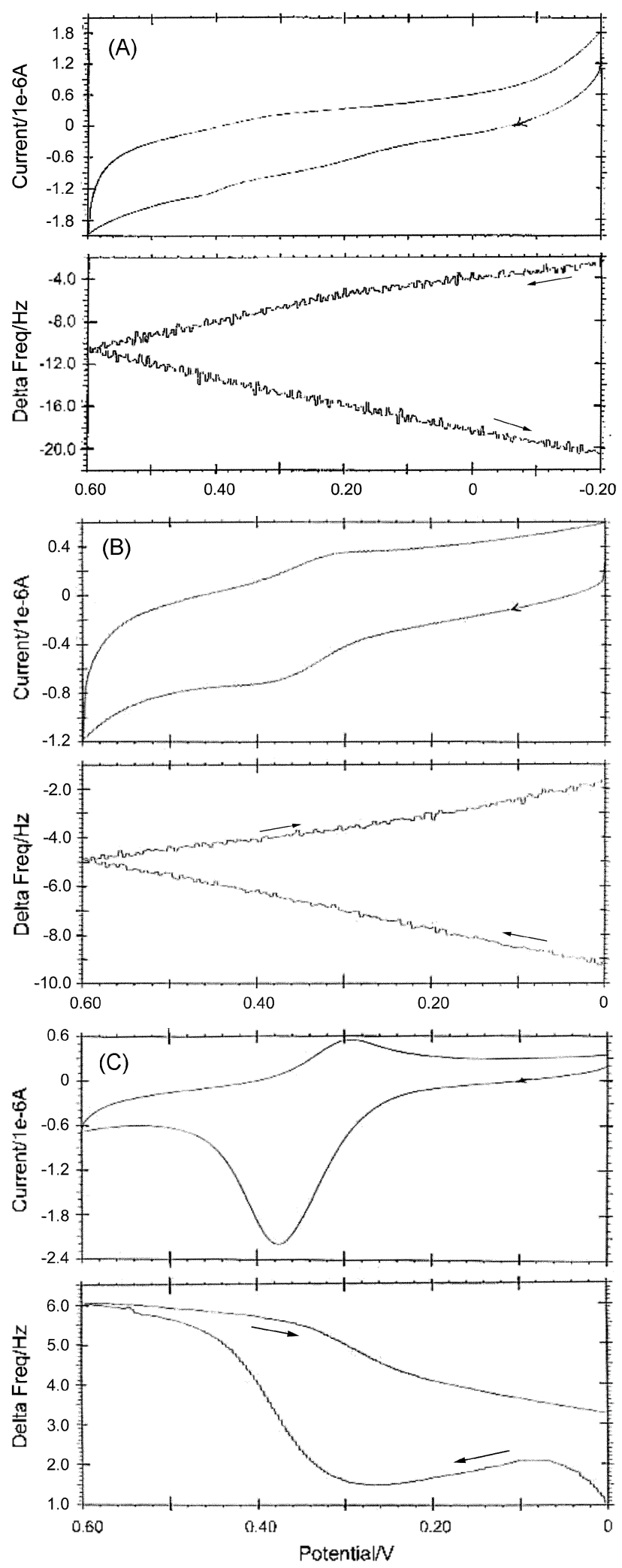

Figure 7. Time dependence of freguency and the corresponding CV results for the quartz erystal resonator in (A) $1 \mathrm{mM}$ act/ethanol solution and $(B)$ in $1 \mathrm{mM}$ 3.4-dihydroxyphenylalanine containing 3 $\mathrm{mV}$ b:ISC solution. which was used to prepare the $\mathrm{OC} \wedge(\mathrm{Au})$ datdpa type electrode $\Lambda$ and (C) $Q C \wedge(\Lambda u) / a e t-d p a-N \wedge D I I$ electrode with $1.21 \mathrm{mM}$. VADH where the gate time $=0.1 \mathrm{~s}$. output range $=$ $20 \mathrm{kH} / . \mathrm{F}^{\circ} \quad 7.993 .804 \mathrm{H} /$. surlace coverage $1.05 \times 10^{-13}$ mol $\mathrm{cm}^{-2}$. and active electrode area $=0.205 \mathrm{~cm}^{2}$. 


$$
\Delta \mathrm{m}=1.40 \times 10^{-8} \mathrm{gHz}^{-1} \mathrm{~cm}^{-2} \Delta \mathrm{F}
$$

Figure 7A exhibited the continuous increasing in frequency observed in the one CV measurements of the QCA(Au)/aet electrode. The terminal anine groups, which incorporated the large molecules of the supporting electrolyte. tris(hydroxymethyl) aninomethane, are electronically charged or discharged during the $\mathrm{CV}$ process and. consequently. the counterbalancing ions trapped on the film cannot escape. This leads to a capacitive charging or discharging of the films and build-up of the electrostatic field. The field will eventually exceed the threshold frequency jump necessary to expel excess ions. ${ }^{13}$ However. on the other hand, the surface of the SAMs, which are covered with hydroxyl groups. is in contacts with the solution, as shown in Scheme 1, in Figure 7B. The well oriented surface could be more easily hydrated. and this hydration might be sufficient to absorb the excess ions produced when they were oxidized to the o-quinone or reduced to the o-hydroquinone form, resulting in continuous decrease in frequency. The reaction of the QCA(Au)/aet-dpa type of electrode with $\mathrm{NADH}$ gave rise to a different pattern of redox process, as shown in Figure $7 \mathrm{C}^{14}$ The oxidation process at $-0.30 \mathrm{~V}$ exhibited a sudden increase in frequency of $4.3 \mathrm{~Hz}$ originated from the oxidation of $\mathrm{NADH}$ to $\mathrm{NAD}^{+}$.

\section{Conclusions}

The oxidation of o-hydroquinone moiety in the SAMs on the gold electrodes gave rise to stable redox active thin films. The analytical signal was based on the electrocatalytic oxidation of the NADH on the gold electrode, inmobilized by 2-aminoethanethiol and subsequently modified with 3,4 dihydroxyphenylalanine, which resulted in $\mathrm{Au} / \mathrm{aet}-\mathrm{dpa}$ the type of electrode. The electrodes gave well ordered film morphology. lower formal potential (0.30 V is SSCE). a 9 times higher rate constant of charge transfer and 10 tines higher detection limit than the polymer modified one. We characterized the response of the biosensor in terms of the effects of the immobilization procedure and $\mathrm{pH}$ of the solution. The $0.1 \mathrm{M}$ Tris $/ \mathrm{NO}_{3}{ }^{-}$buffer solution $(\mathrm{pH}=8.0)$ gave the best electrochemical responses at a slow scan rate of 0.01 $\mathrm{Vs}^{-1}$. The biosensor exhibited high sensitivity with a limit of detection in the $3.8 \mathrm{mM}$ range, and the rate constant $\left(\mathrm{k}_{\mathrm{f}}\right)$ was $2.17 \times 10^{4} \mathrm{M}^{-1} \mathrm{~s}^{-1}$. This modified electrode. when employed as a biosensor. could be useful in the electrocatalytic oxidation of $\mathrm{NADH}$. These reactions eventually become deficient owing to the coupling reactions of dpa itself at the modification of the Au/aet electrodes. However sufficient amount of dpa could overcome this process.

Acknowledgmemt. This work proceeded with the financial support of Kyungnam University (2003. AY).

\section{References}

1. Poirer. B. E.: Pylant. E. D. Science 1996, 272. 1145.

2. Ulman. A. Chem. Rev 1996,96.1533.

3. Dubois. H. L.: Nuzzo. R. G. Amm. Rev Plys. Chem. 1992. 24. 112.

4. Xia. Y.: Whitesides. G. M. Angew: Chem., Int. Ed. Engl. 1998. 37. 550 .

5. Clegg, R. S.; Hutchen, J. E. J. Ant. Chem. Soc. 1999, 121. 5319.

6. Cha. S. K. J. Polnmer Sci. Part B 1997, 35, 165.

7. Lee. T. Y.: Lee. S. J.: Song. T. Y. Bull. Konean Chem. Soc. 2002. $23(11) .1640$.

8. Kim. B. H.: Lee. C. W.: Ko. T. T.: Chang. H. G.: Gong. M. S. Bull. Konean Chem. Soc. 2002. 23(11), 1643.

9. Jaegefelt. H.: Kuwana. T.: Johansson. G. J. An. Chent. Soc. 1983. 105.1805

10. Pariente. F.: Lorenzo. E.: Tobalina. F.: Moreno. G.: Hernandez. L.: Abruna. H. D. Anat. Chem 1997. 69.4065.

11. Pleskox. Y. V: Filinowsii. V. Y. The Rotating Disc Electrode: Consultant Bureau. N. Y. 1976: chp. 2.

12. Buttry, D. A.; Ward. M. D. Chem. Ret 1992, 92. 1355.

13. Hepel. M. Electrochintica Acta 1996. $+1(1), 63$.

14. Kang. J. H. Bull. Korean Chem. Soc. 2004. 25(5). 625. 